\section{SURGICAL MANAGEMENT OF COMPLETE ATRIOVENTRICULAR SEPTAL DEFECTS}

\section{A twenty-year experience}

Creation of a competent left atrioventricular valve is a cornerstone in surgical repair of complete atrioventricular septal defects. To identify risk factors for mortality and failure of left atrioventricular valve repair and to determine the impact of cleft closure on postoperative atrioventricular valve function, we retrospectively analyzed hospital records of 203 patients between January 1974 and January 1995. Overall early mortality was $7.9 \%$. Operative mortality decreased significantly over the period of the study from $19 \%(4 / 21)$ before 1980 to $3 \%(2 / 67)$ after $1990(p=0.03)$. Ten-year survival including operative mortality was $91.3 \% \pm 0.004 \%(95 \%$ confidence limit): all survivors are in New York Heart Association class I or II. Preoperative atrioventricular valve regurgitation was assessed in 203 patients by angiography or echocardiography and was trivial or mild in $\mathbf{1 0 3}$ (52\%), moderate in $82(41 \%)$, and severe in $18(8 \%)$. Left atrioventricular valve cleft was closed in $93 \%(189 / 203)$ but left alone when valve leaflet tissue was inadequate and closure of the cleft might cause significant stenosis. Reoperation for severe postoperative left atrioventricular valve regurgitation was necessary in eight patients, five of whom initially did not have closure of the cleft and three of whom had cleft closure. Six patients had reoperation with annuloplasty and two patients required left atrioventricular valve replacement. Five patients survived reoperation and are currently in New York Heart Association class I or II. On most recent evaluation assessed by angiography or echocardiography (a mean of 59 months after repair), left atrioventricular valve regurgitation was trivial or mild in 137 of the 146 survivors (94\%) examined; none had moderate or severe left atrioventricular valve stenosis. By multiple logistic regression analysis, strong risk factors for early death and need for reoperation included postoperative pulmonary hypertensive crisis, immediate postoperative severe left atrioventricular valve regurgitation, and double-orifice left atrioventricular valve. These results indicate that complete atrioventricular septal defects can be repaired with low mortality and good intermediate to long-term results. Routine approximation of the cleft is safe and has a low incidence of reoperation for left atrioventricular valve regurgitation. (J THORAC CARDIOVASC SURG 1995;110:1543-54)

Ko Bando, MD, ${ }^{\text {a }}$ (by invitation), Mark W. Turrentine, MD, ${ }^{a}$ (by invitation), Kyung Sun, MD, (by invitation), Thomas G. Sharp, MD, (by invitation), Gregory J. Ensing, MD, ${ }^{\mathrm{b}}$ (by invitation), Andrew P. Miller, BS, ${ }^{a}$ (by invitation), Kenneth A. Kesler, MD, ${ }^{a}$ (by invitation), Robert S. Binford, MD, ${ }^{\text {a }}$ (by invitation), Glenn N. Carlos, MD, ${ }^{a}$ (by invitation), Roger A. Hurwitz, MD, ${ }^{\text {b }}$ (by invitation), Randall L. Caldwell, MD, ${ }^{\mathrm{b}}$ (by invitation), Robert K. Darragh, MD, ${ }^{\mathrm{b}}$ (by invitation), Joyce Hubbard, $\mathrm{MD},{ }^{\mathrm{b}}$ (by invitation), Timothy M. Cordes, MD, ${ }^{b}$ (by invitation), Donald A. Girod, MD, ${ }^{b}$ (by invitation), Harold King, MD, ${ }^{a}$ and John W. Brown, MD, ${ }^{a}$ Indianapolis, Ind.
From the Section of Cardiothoracic Surgery, ${ }^{a}$ Division of Pediatric Cardiology. ${ }^{b}$ Indiana University School of Medicine. Indianapolis, Ind.

Read at the Seventy-fifth Annual Meeting of The American Association for Thoracic Surgery, Boston, Mass., April 23-26, 1995.
Address for reprints: John W. Brown, MD, Section of Cardiothoracic Surgery, Indiana University Medical Center, Emerson Hall Room 212, 545 Barnhill Dr., Indianapolis, IN 46202.

Copyright (C) 1995 by Mosby-Year Book, Inc.

$0022-5223 / 95 \$ 5.00+0 \quad \mathbf{1 2 / 6 / 6 8 2 4 5}$ 
$R^{\sin }$ eports of surgical management of atrioventricular (AV) septal defects over the past 20 years indicate a general trend of steady decline in perioperative mortality. ${ }^{1-3}$ However, left $\mathrm{AV}$ valve regurgitation remains a critical hemodynamic complication in patients surviving repair of AV septal defects, ${ }^{1,4,5}$ and the creation of a competent left AV valve is a cornerstone in successful surgical repair. ${ }^{2,6}$ Accordingly, we reviewed the results of surgical correction of complete AV septal defects to identify risk factors for mortality and failure of left $A V$ valve repair and to determine the impact of cleft closure on postoperative AV valve function.

\section{Patients and methods}

Clinical data. This study includes the last 203 patients undergoing definitive repair of complete AV septal defects at our institution from January 1974 to January 1995 and observed through March 31, 1995. All patients with forms of the AV septal defect in which no interventricular communication (or so small as to not require patch closure) was present by ventriculography or echocardiography were excluded from the study population. By using these criteria, we avoided a "transitional" AV septal defect subset.

All patients in whom both palliative procedure and definite repair were performed at our institution were included in this population. Patients who received palliation at other institutions and then were referred to our institution were excluded from the study population. Patients who received palliation in our institution but died before definite repair or had definite repair elsewhere were not included in this study (Appendix I).

Patients with associated cardiovascular and noncardiovascular lesions were included with the following exceptions. Those with complicated coexisting cardiac anomalies (i.e., transposition of great arteries, total anomalous pulmonary venous return) were excluded because the presence of these anomalies changes the basic physiology and natural history of the patient. Also patients with significantly unbalanced defects who required singleventricle repair or bidirectional Glenn shunt associated with definitive repair of AV canal were excluded.

Down's syndrome was present in 160 patients $(78.8 \%)$. Ages ranged from 2 months to 204 months (median 14 months) at the time of complete repair. There were 112 girls and 91 boys. Weight at operation ranged from 2.4 to $40.0 \mathrm{~kg}$ (mean $9.1 \mathrm{~kg}$ ). Twelve patients $(5.9 \%)$ were born prematurely (defined as <36-week gestational age and birth weight $<2.5 \mathrm{~kg}$ ).

Ninety-one patients $(44.8 \%)$ underwent palliative pulmonary artery banding before repair. The reasons for this included multiple ventricular septal defects (VSDs), associated preoperative noncardiac illness, significant ventricular imbalance, and preference of the referring cardiologists. Two patients had aortic coarctation repair and one patient had patent ductus ligation before complete repair. Another two patients with combined tetralogy and complete AV septal defects had a Blalock-Taussig shunt before definitive repair. Since 1990, we have adopted an approach of early primary repair reserving pulmonary artery banding for neonates with complicated associated anomalies.

Preoperative evaluation. Patients routinely underwent preoperative cardiac catheterization. Echocardiography also has been routinely performed since 1978. According to cardiac catheterization or echocardiography, preoperative left $\mathrm{AV}$ valve regurgitation was trivial or mild in 103 patients $(50.7 \%)$, moderate in 82 patients $(40.4 \%)$, and severe in 18 patients $(8.9 \%)$. Preoperative right AV valve regurgitation was trivial or mild in 187 patients $(92.2 \%)$, moderate in 14 patients $(6.9 \%)$, and severe in 2 patients $(1.0 \%)$.

Cardiac anomalies associated with complete AV septal defects are shown in Table I. A left-sided outflow tract obstructive lesion was present in 10 patients (4.9\%). Six patients $(3.0 \%)$ had double-orifice left AV valve, and single left-sided papillary muscle was present in 3 patients $(1.5 \%)$.

The AV valve structure was classified according to the Rastelli designation ${ }^{7}$ with the exception of those cases in which there were two separate left AV valves. A total of 129 valves were classified as type A (63.5\%), 4 classified as type B $(2.0 \%)$, and 68 classified as type C (33.5\%).

Operative management. Our operative management has evolved during our 20 years of experience. A median sternotomy is performed, adhesions if present are freed, and the external cardiac anatomy is assessed. Cannulation is accomplished by using the ascending aorta for arterial inflow and separate caval cannulas inserted through the right atrial appendage or superior vena cava, or both, for venous outflow to the pump. A small foam pad is inserted behind the heart to insulate the heart from the left phrenic nerve and the warmer mediastinal structures. Cardiopulmonary bypass is instituted at a flow rate of $2.4 \mathrm{~L} / \mathrm{min}$ per square meter and the perfusate is cooled to $20^{\circ}$ to $28^{\circ} \mathrm{C}$. The left side of the heart is vented with a catheter inserted through the apex of the left ventricle and the aorta is crossclamped. Cold crystalloid cardioplegic solution is injected to a total volume of $15 \mathrm{ml} / \mathrm{kg}$. Topical hypothermia is added. The infusion of cardioplegic solution is repeated in 20 to 25 minutes, or sooner if electrical activity is noted.

A careful assessment is made of the intracardiac anatomy with particular reference to the AV valves. The chordal attachments to the margins of the left and right $\mathrm{AV}$ valve orifices are noted. Cold saline solution is inserted in the left ventricular vent to "float" the AV valve leaflets into apposition. The superior and inferior bridging valve tissue and their supporting chordal structures are not divided but left intact (Fig. 1, $A$ ). Interrupted horizontal mattress sutures of 6-0 polytetrafluoroethylene suture are placed in the left AV valve cleft, first at the base and then carried toward the free edge of the left AV valve orifice (Fig. 1, B). These sutures are left untied and the leaflets are retracted until the septal portion of the VSD patch is inserted. The VSD patch is constructed from soft knitted Dacron velour and fashioned in a half-moon shape. The VSD patch is sutured to the right side of the crest of the ventricular septum with 5-0 polypropylene suture beginning under the superior bridging leaflet and 
carried inferiorly. A single over-and-over technique alternating with a horizontal mattress technique is used to avoid entrapment of any of the right AV valve chordal structures.

Once the septal portion of the VSD patch is secured, the previously placed cleft sutures are tied. Drawing the cleft sutures together drapes the superior and inferior bridging leaflets over the upper margin of the VSD patch in a relaxed fashion. A separate 5-0 polypropylene suture secures the bridging leaflets to the upper margin of the VSD patch (Fig. 1, C). The left ventricle is again filled through the left ventricular vent catheter to confirm complete closure of the VSD and good approximation of the reconstructed left $A V$ valve.

A generous rectangle of fresh pericardium is then harvested and placed with the mesothelial surface toward the left AV valve orifice. A separate 5-0 polypropylene sutures is used to close the primum atrial septal defect (ASD) beginning at the cleft closure and running in both directions. Care should be taken that neither the VSD nor ASD patches places any tension on the left AV valve. Inferiorly the ASD suture line is carried off the inferior bridging leaflet onto the left AV valve anulus and under the coronary sinus until the atrial septal tissue is encountered (Fig, 1,D). The pericardium is then trimmed until it fits into the remainder of the ASD in a relaxed fashion. Fig. 1, $E$ shows the completed repair before the right atrium is closed.

In the early 88 patients in our series, a single Dacron patch technique was used for repair. ${ }^{8}$ In the recent 115 $(57 \%)$ patients, the two-patch repair technique described earlier was used. ${ }^{1,9}$ Although the one-patch technique gave acceptable results, we changed to the two-patch technique because we believed it produces less AV valve distortion. The avoidance of dividing the superior and inferior bridging leaflets was appealing because of the rare incidence of dehiscence of the delicate leaflets from the VSD patch when they were divided. The pericardial ASD patch completely eliminated the occasional occurrence of postoperative hemolysis when a small jet through the left $A V$ valve struck the Dacron ASD patch. The left AV valve cleft was closed in 93.1\% (189/203) but left alone when valve leaflet tissue was insufficient and closure of the cleft might cause significant stenosis. A more complex valvuloplasty (i.e., chordal shortening) or annuloplasty (or both) was required in four patients.

Intraoperative postrepair evaluation and monitoring. As the patient is being warmed and weaned from bypass, left atrial, pulmonary artery, and right atrial oximetric monitoring catheters are inserted for intraoperative postrepair and postoperative monitoring. Since August 1990, transesophageal echocardiography has been routinely used to further assess the completeness of repair. On rare occasions, reinstitution of bypass for further repair of the left or right AV valves or VSD was necessary if the echocardiogram showed more than mild regurgitation or more than a trivial shunt. The combination of invasive monitoring and transesophageal echocardiography allows us to better quantitate the findings of echocardiography (Fig. 2).

Intravenous nitroglycerin at a dosage of 0.5 to $10 \mu \mathrm{g} / \mathrm{kg}$ per minute is currently the most common drug given in the early postoperative period. It is administered via the right
Table I. Cardiac anomalies associated with complete AV septal defects

\begin{tabular}{lcr}
\hline \multicolumn{1}{c}{ Anomalies } & No. of patients & $\%$ \\
\hline ASD secundum & 50 & 24.9 \\
PDA & 48 & 23.6 \\
Multiple VSDs & 7 & 3.4 \\
DORV & 6 & 3.0 \\
TOF & 3 & 1.5 \\
Left SVC & 4 & 2.0 \\
Left-sided obstructive region & 10 & 4.9 \\
Double-orifice left AV valve & 6 & 3.0 \\
Single left-sided papillary muscle & 3 & 1.5 \\
\hline
\end{tabular}

$\overline{A S D}$, Atrial septal defect; $P D A$, patent ductus arteriosus; $V S D$, ventricular septal defect; $D O R V$, double-outlet right ventricle; $T O F$, tetralogy of Fallot; SVC, superior vena cava.

atrial or pulmonary arterial line to attempt to keep the pulmonary artery pressure less than $40 \%$ of systemic pressure. If dopamine is required in a dosage of more than 5 $\mu \mathrm{g} / \mathrm{kg}$ per minute, it is delivered via the left atrial line in an attempt to reduce its potential pulmonary vasoconstrictive effects. Administration of chlorpromazine is begun in the immediate postoperative period in a dosage of 0.5 to $2.0 \mathrm{mg}$ every 4 hours for its pulmonary vasodilatory ( $\alpha$-adrenergic blockade) and central nervous system sedative effects.

If pulmonary hypertension ( $>50 \%$ of systemic pressure) persists after chlorpromazine in a dosage of $2 \mathrm{mg}$ every 4 hours is given, then prazosin hydrochloride (another $\alpha$-adrenergic blocker) is given orally or by nasogastric tube in dosages beginning with $0.25 \mathrm{mg}$ every 4 hours and increasing gradually until an upper limit of $2 \mathrm{mg}$ every 4 hours is reached. If a patient requires chlorpromazine or prazosin hydrochloride for control of pulmonary hypertension, then one or both are continued for 2 to 4 weeks orally after discharge and the dosage is gradually reduced. Most patients were given digoxin and furosemide in standard doses for the first 1 to 2 months after the operation. Invasive cardiac monitoring lines are left in place for 1 to 5 days depending on the degree of pulmonary vasoreactivity. Most patients were extubated on the first or second postoperative day. The average length of hospital stay since 1990 has been 9 days.

Postoperative evaluation. A complete set of postoperative physiologic data was available in 175 patients $(81.3 \%)$, including rhythm, pacemaker requirement, inotropic requirement, systemic arterial and pulmonary arterial pressures, right and left atrial pressures, and right atrial and pulmonary arterial oxygen saturations.

Evidence of significant postoperative left $\mathrm{AV}$ valve regurgitation by echocardiography or catheterization was evaluated carefully (Fig. 2). Early (perioperative) death was defined as occurring within 30 days of the operation or before hospital discharge after repair. Failure of left $\mathrm{AV}$ valve repair was defined as residual severe regurgitation that necessitated reoperation. Reoperations were analyzed and cause of reoperation was categorized as residual intracardiac shunt, left AV valve dysfunction, rhythm disturbance, or other. Timing of reoperation after repair was recorded. Other postoperative complications including neurologic, respiratory, and infectious complications were also noted. 

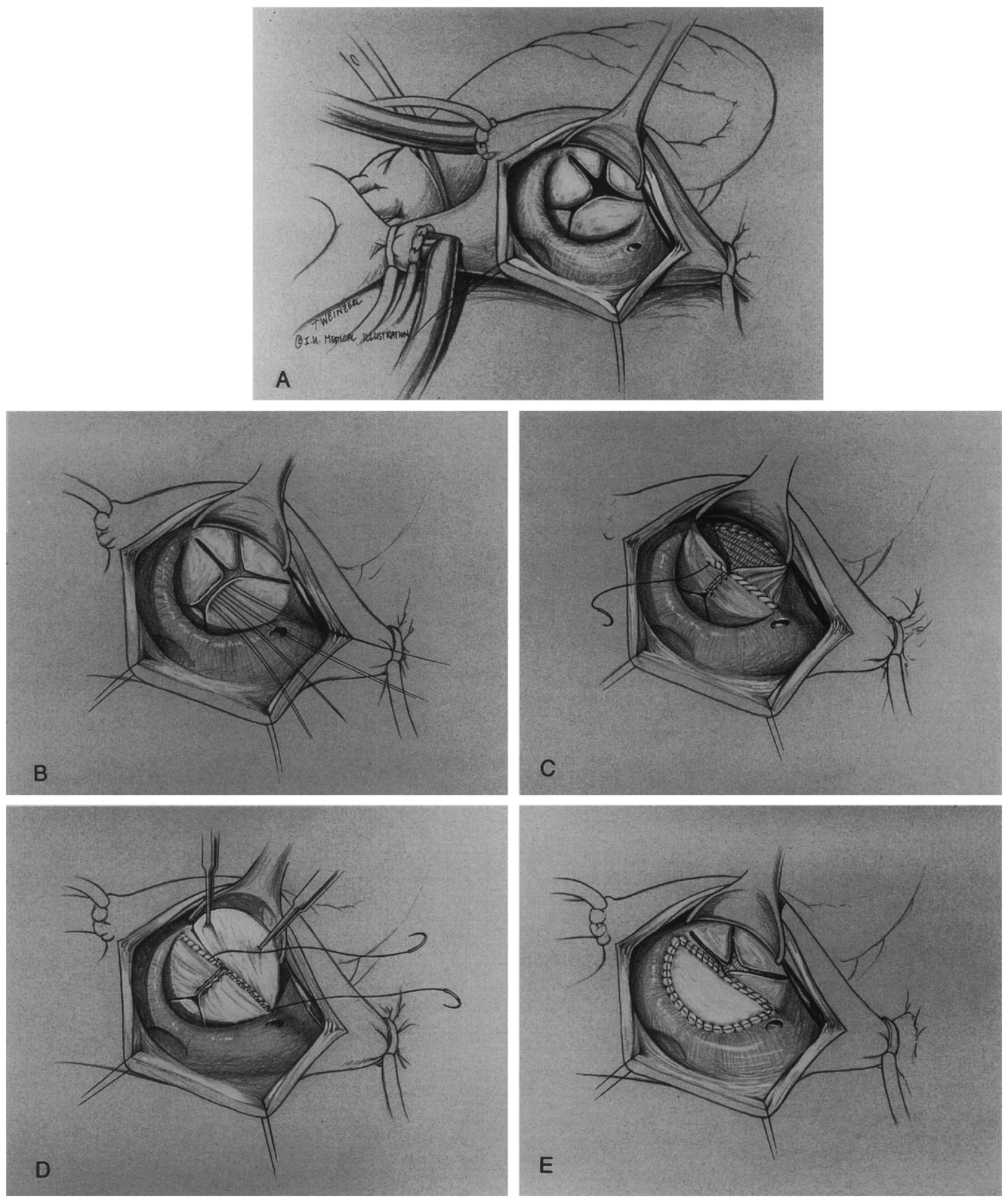

Fig. 1. A to E, Surgical technique of complete AV septal repair. See details in the text. 


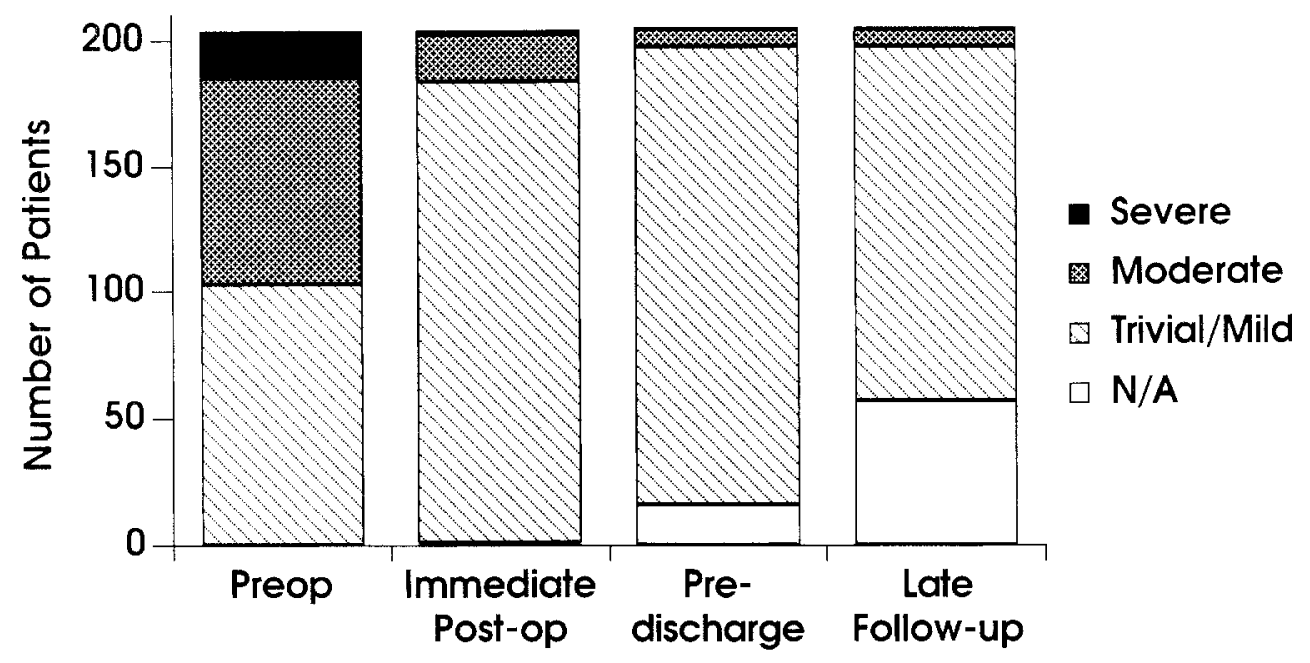

Fig. 2. Sequential assessment of left AV valve function before and after repair of complete AV septal defects. $N / A$, Not available.

Postoperative patient status was determined by direct evaluation of the patient by the pediatric cardiologist and surgeon or by letters from referring physicians. If recent ( $<6$ months) follow-up had not been accomplished, the patients were contacted directly by telephone during the months of January, February, and March 1995.

Statistical analysis. Data were entered into a computerized database and analyzed with Statistica software (Statsoft, Inc., Tulsa, Okla.). The cumulative survival estimates of patients were made by the actuarial (lifetable) method and the $95 \%$ confidence intervals for the estimates were determined by the Greenwood formula. ${ }^{8}$ The trends in patient population and surgical technique in each 5-year period were analyzed by analysis of variance.

The multiple logistic regression model was used to identify the independent contribution of potential risk factors for patient mortality and failure of left AV valve repair in the total cohort of 203 patients. The variables entered into the risk factor analysis are summarized in Appendix 2. The selection of independent variables in the models was a forward stepwise method with a critical $p$ value for variable inclusion and exclusion of 0.15 . A $p$ value of less than 0.05 was considered significant.

\section{Results}

Early and late mortality. There were 16 early deaths $(7.9 \%)$. Operative mortality decreased significantly over the period of the study from $19 \%(4 / 21)$ before 1980 to $3 \%(2 / 67)$ after $1990(p=0.03)$. Primary causes of early death are shown in Table II. Six patients were lost to follow-up. Follow-up in the remaining 197 patients ranged from 2.2 months to 233.9 months (19.5 years) with a median of 94.5 months (7.1 years). Two patients died late, 4 and 8 months after the operation, of sepsis and congestive heart failure. Overall survival, including early
Table II. Primary cause of early death

\begin{tabular}{lc}
\hline \multicolumn{1}{c}{ Causes } & No. of patients \\
\hline Pulmonary hypertensive crisis & 6 \\
Acute ventricular failure & 4 \\
Sepsis & 2 \\
Arrhythmia & 2 \\
Multisystem organ failure & 2 \\
Total mortality & $16(7.9 \%)$ \\
\hline
\end{tabular}

deaths, was $91.3 \% \pm 0.04 \%$ at 1 and 10 years after the operation (Fig. 3).

Risk factors associated with early death are shown in Table III. By multivariate analysis, pulmonary hypertensive crisis, immediate severe postoperative left $\mathrm{AV}$ valve regurgitation, double-orifice left $\mathrm{AV}$ valve, and prematurity were the significant risk factors for early death. By multivariate analysis, neither preoperative pulmonary hypertension nor preoperative severity of left $\mathrm{AV}$ valve regurgitation predicted early death.

Survival in patients with moderate or severe left $A V$ valve regurgitation immediately after the operation was significantly less than survival of patients with trivial or mild left $A V$ valve regurgitation at 1 month and 1,5 , and 10 years after the operation. All deaths in patients with moderate or severe left AV valve regurgitation occurred within the first year after the operation. Survival at 1 month and 1,5, and 10 years after the operation of patients who had a postoperative pulmonary hypertensive crisis was also significantly less than that of patients without a pulmonary hypertensive crisis. Risk of mortality in 


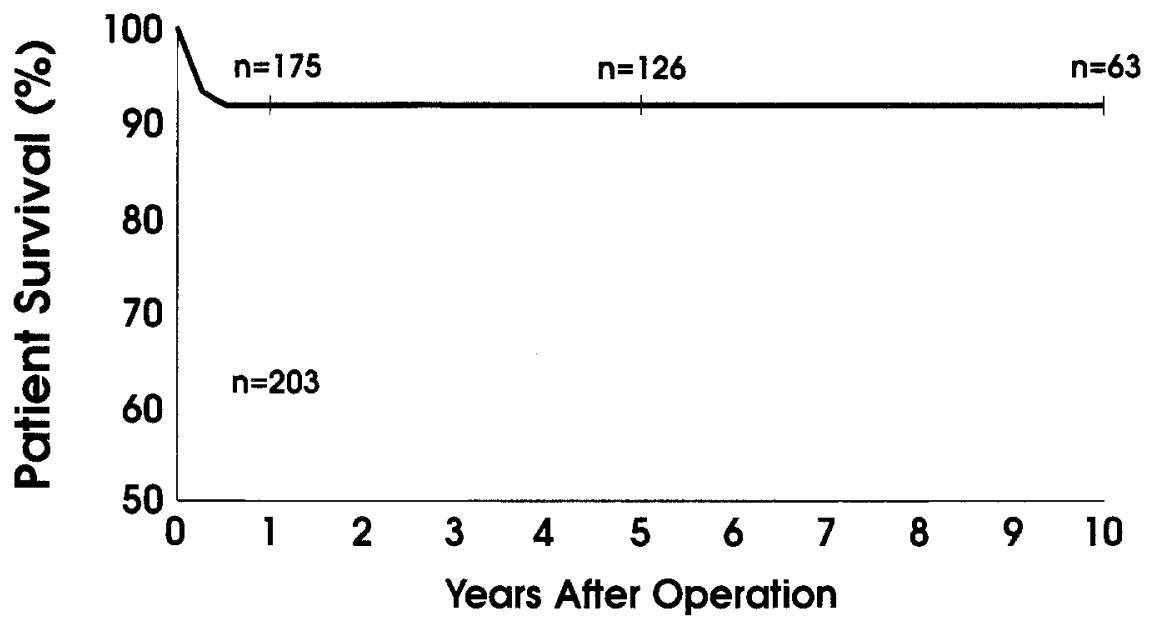

Fig. 3. Patient survival including early mortality. Vertical bars enclose a $95 \%$ confidence interval.

Table III. Risk factors for early death

\begin{tabular}{lll}
\multicolumn{1}{c}{ Factors } & $\begin{array}{c}\text { Univariate } \\
(p \text { value })\end{array}$ & $\begin{array}{c}\text { Multivariate } \\
(p \text { value })\end{array}$ \\
\hline Pulmonary hypertensive crisis & $<0.0001$ & $<0.0001$ \\
Severe left AV valve regurgitation & $<0.001$ & $<0.001$ \\
$\quad$ in the immediate postop. period & & \\
Double-orifice left AV valve & $<0.0001$ & 0.02 \\
Prematurity & $<0.001$ & 0.02 \\
Left-sided obstructive lesion & $<0.001$ & $\mathrm{NS}$ \\
Requirement of pacemaker & $<0.01$ & $\mathrm{NS}$ \\
Preop. severe left AV valve & 0.01 & $\mathrm{NS}$ \\
$\quad$ regurgitation & & \\
NS, Not significant. & &
\end{tabular}

Table IV. Major reoperation after repair of complete AV septal defects

\begin{tabular}{lc}
\hline \multicolumn{1}{c}{ Reoperations } & No. of patients \\
\hline Left AV valve regurgitation & 8 \\
Residual VSD & 3 \\
Permanent pacemaker implantation & 5 \\
RVOT reconstruction & 1 \\
Apicoaortic conduit & 1 \\
Total reoperations & $18(8.9 \%)$ \\
\hline
\end{tabular}

$V S D$, Ventricular septal defect; RVOT, right ventricular outflow tract.

patients with a postoperative pulmonary hypertensive crisis was highest during the first 3 months after the operation.

Preoperative and early and late postoperative evaluation of left $\mathrm{AV}$ valve. Left $\mathrm{AV}$ valve regurgitation was evaluated before the operation, during or immediately after the operation, at discharge, and late after repair of complete AV septal defects (see Fig. 2). Diagnostic technique in- cluded cineangiography (preoperative, late postoperative), transthoracic echocardiography (preoperative, immediately after operation, at discharge, and at late follow-up) and transesophageal echocardiography (immediately after operation). Immediate postoperative evaluation included transthoracic echocardiography in the intensive care unit before July 1990 and intraoperative postrepair transesophageal echocardiography after August 1990. Immediately after repair, $90 \%$ of patients had less than moderate regurgitation and $9.5 \%$ of patients had moderate regurgitation. At the time of discharge, the results were further improved and $96 \%$ of 187 operative survivors had less than moderate regurgitation. At a median of 59 months (range from 2.8 to 194.6 months) after the operation, results of late postoperative left AV valve function were available for 146 patients $(71.9 \%)$. One hundred forty patients had trivial or mild left $\mathrm{AV}$ valve regurgitation, and six patients had moderate left $\mathrm{AV}$ valve regurgitation (see Fig. 2). None of these 146 patients had moderate or severe left AV valve stenosis.

Reoperation. Seventeen patients underwent one reoperation or more performed over a range of 3 to 72 days after the initial repair (Table IV). Three patients required reoperation for residual VSD and one of them required combined annuloplasty and a second VSD patch closure because of severe regurgitation and residual intracardiac shunt. Five patients required pacemaker implantation because of complete $(n=1)$ or second-degree heart block $(n=$ $2)$, postoperative sinus bradycardia $(n=1)$, and syncopal episodes $(n=1)$. Eight patients required 
Table V. Reoperation because of left $A V$ valve regurgitation

\begin{tabular}{|c|c|c|c|c|c|c|c|c|c|c|c|}
\hline \multirow[b]{2}{*}{$\begin{array}{l}\text { Patient } \\
\text { (by year) }\end{array}$} & \multicolumn{3}{|c|}{ Initial operation } & \multirow[b]{2}{*}{$\begin{array}{c}\text { Associated } \\
\text { anomaly }\end{array}$} & \multicolumn{3}{|c|}{ Left $A V$ valve regurgitation } & \multirow[b]{2}{*}{$\begin{array}{l}\text { Type of } \\
\text { reoperation }\end{array}$} & \multirow[b]{2}{*}{$\begin{array}{l}\text { Days } \\
\text { after finst } \\
\text { operation }\end{array}$} & \multirow[b]{2}{*}{ Survival } & \multirow[b]{2}{*}{$\begin{array}{l}\text { Current left } \\
\text { AV valve } \\
\text { regurgitation }\end{array}$} \\
\hline & $\begin{array}{l}\text { Cleft } \\
\text { closure }\end{array}$ & $\begin{array}{l}\text { Annulo- } \\
\text { plasty }\end{array}$ & $\begin{array}{l}\text { Valvulo- } \\
\text { plasty }\end{array}$ & & $\begin{array}{l}\text { Before } \\
\text { first } \\
\text { operation }\end{array}$ & $\begin{array}{l}\text { Immediately } \\
\text { after first } \\
\text { operation }\end{array}$ & $\begin{array}{l}\text { Before } \\
\text { reoperation }\end{array}$ & & & & \\
\hline 1 & - & - & - & $\begin{array}{l}\text { Minimal left } \\
\text { AV valve } \\
\text { leaflet } \\
\text { tissue }\end{array}$ & Severe & Moderate & Severe & $\begin{array}{l}\text { Annuloplasty, } \\
\text { redo VSD } \\
\text { patch }\end{array}$ & 36 & $\mathrm{Y}$ & Mild \\
\hline 2 & + & - & - & $\begin{array}{c}\text { Dehiscence } \\
\text { of cleft }\end{array}$ & Moderate & Mild & Severe & $\begin{array}{l}\text { Annuloplasty, } \\
\text { reapproxima- } \\
\text { tion of the } \\
\text { cleft }\end{array}$ & 5 & $\mathrm{Y}$ & Mild \\
\hline 3 & - & - & - & $\begin{array}{l}\text { Minimal left } \\
\text { AV valve } \\
\text { leafiet } \\
\text { tissue }\end{array}$ & Moderate & Mild & Severe & $\begin{array}{l}\text { Valvuloplasty, } \\
\text { left AV valve } \\
\text { replacement }\end{array}$ & 18 & $\mathrm{~N}$ & - \\
\hline 4 & - & - & - & $\begin{array}{l}\text { Double-orifice } \\
\text { left AV } \\
\text { valve, } \\
\text { bypoplastic } \\
\text { left ventricle }\end{array}$ & Moderate & Moderate & Severe & Annuloplasty & 3 & $\mathrm{~N}$ & - \\
\hline 5 & + & + & - & $\begin{array}{l}\text { Dehiscence } \\
\text { of cleft } \\
\text { suture }\end{array}$ & Severe & Mild & Severe & $\begin{array}{l}\text { Reapproxima- } \\
\text { tion of the } \\
\text { cleft }\end{array}$ & 62 & Y & Mild \\
\hline 6 & + & - & - & $\begin{array}{l}\text { SBE, dehis- } \\
\text { cence of } \\
\text { cleft of cleft }\end{array}$ & Moderate & Mild & Severe & $\begin{array}{l}\text { Closure of per- } \\
\text { foration, reap- } \\
\text { proximation } \\
\text { of the cleft }\end{array}$ & 72 & Y & Mild \\
\hline 7 & -- & - & - & $\begin{array}{l}\text { Asymmetric } \\
\text { left AV } \\
\text { valve }\end{array}$ & Moderate & Mild & Moderate & Annuloplasty & 18 & $\mathrm{Y}$ & Mild \\
\hline 8 & - & - & - & $\begin{array}{l}\text { Double- } \\
\text { orifice left } \\
\text { AV valve }\end{array}$ & Severe & Moderate & Severe & $\begin{array}{l}\text { Left AV valve } \\
\text { replacement }\end{array}$ & 8 & $N$ & - \\
\hline
\end{tabular}

reoperations because of residual severe left AV valve regurgitation after the initial operation (Table V); five patients initially did not have cleft closure because of inadequate left $\mathrm{AV}$ valve tissue. Three patients had separation of initial cleft closure because of subacute endocarditis $(n=1)$ and unknown reasons $(n=2)$.

Factors associated with any reoperation and reoperation for left AV valve regurgitation were analyzed by univariate and multivariate logistic regression (Tables VI and VII). By multiple logistic regression, double-orifice left AV valve, preoperative and immediate postoperative severe AV valve regurgitation, significant step-up of oxygen saturation between the right atrium and pulmonary artery (pulmonary/systemic flow ratio $>1.5$ ), and pulmonary hypertensive crisis were the risk factors for overall reoperation. Immediate postoperative severe left $A V$ valve regurgitation and double-orifice
Table VI. Risk factors for major reoperation

\begin{tabular}{lcc} 
Factors & $\begin{array}{c}\text { Univariate } \\
(p \text { value })\end{array}$ & $\begin{array}{c}\text { Multivariate } \\
(p \text { value })\end{array}$ \\
\hline $\begin{array}{l}\text { Double-orifice left AV valve } \\
\text { Preop. severe left AV valve } \\
\text { regurgitation }\end{array}$ & $<0.0001$ & 0.001 \\
$\quad<0.001$ & 0.001 \\
Immediate postop. severe & 0.001 & 0.001 \\
left AV valve regurgitation & & \\
RA-PA oxygen step-up & 0.005 & 0.003 \\
$\begin{array}{l}\text { Pulmonary hypertensive crisis } \\
\text { Total CPB time }\end{array}$ & 0.006 & 0.003 \\
& 0.02 & $\mathrm{NS}$
\end{tabular}

$R A$, Right atrium; $P A$, pulmonary artery; $C B P$, cardiopulmonary bypass; $N S$, not significant.

left $A V$ valve predicted the requirement of reoperation for residual left AV valve regurgitation.

Other trends over the past 20 years. The proportion of patients with palliative pulmonary artery band has decreased significantly from $76.2 \%$ before 
Table VII. Risk factors for reoperation resulting from residual left $A V$ valve regurgitation

\begin{tabular}{ccc}
\hline Factors & $\begin{array}{c}\text { Univariate } \\
(p \text { value })\end{array}$ & $\begin{array}{c}\text { Multivariate } \\
(p \text { value })\end{array}$ \\
\hline $\begin{array}{c}\text { Double-orifice left AV valve } \\
\text { Immediate postop. severe left } \\
\text { AV valve regurgitation }\end{array}$ & $<0.001$ & $<0.001$ \\
$\begin{array}{c}\text { Preop. severe left AV valve } \\
\text { regurgitation }\end{array}$ & $<0.001$ & $<0.001$ \\
Postop. bleeding & 0.03 & $\mathrm{NS}$ \\
\hline
\end{tabular}

NS, Not significant.

1979 to $28.4 \%$ after $1990(p<0.001$ by analysis of variance). Before 1979 more than $80 \%$ of the repairs were performed with a classic single patch technique but $97 \%$ of repairs were performed with the twopatch technique after $1990(p<0.001$ by analysis of variance). The proportion of patients with postoperative pulmonary hypertensive crises has decreased substantially (Table VIII).

\section{Discussion}

Since the first successful repair of complete AV septal defects by Lillehei in $1954,{ }^{10}$ operative mortality has declined from almost $50 \%$ in early reports to $3 \%$ to $6 \%$ recently. ${ }^{2,5,11}$ In our institution, the operative mortality of complete AV septal defects has also significantly decreased from $19 \%$ before 1980 to $3 \%$ after 1990 with an overall mortality rate of $7.9 \%$. The improvement in surgical results in recent years is likely related to a greater understanding of the structure of this lesion, improved perfusion methods, improved myocardial protection, improved intraoperative transesophageal echocardiographic assessment, and improved postoperative management. However, despite these improvements in early mortality, failure of achieving a competent left $A V$ valve remains the most significant cause of early and late deaths and need for reoperation., 3, 12

The choice of one-patch versus two-patch repair and effect of cleft closure have been controversial. In our institution, the single patch technique was used through 1986, and we converted to a two-patch technique after 1987 (Table VIII). Both techniques provided good early and late results, and no statistically significant difference was observed in early and late mortality or need for reoperation between the two groups. However, our current preference is the two-patch technique because we believe avoiding division of the bridging leaflet with type $\mathrm{C}$ defects, which is always necessary in the single patch technique, can be avoided. ${ }^{13}$ Excellent visualization of the common $\mathrm{AV}$ valve apparatus is possible by both techniques. ${ }^{12}$

Although repair techniques of AV septal defects have evolved over the past 20 years, the cleft of left AV valve has been routinely closed in 93\% (189/ 203 ) of patients except when valve leaflet tissue was inadequate or cleft closure might cause significant stenosis. With this consistent approach for 20 years, left $\mathrm{AV}$ valve regurgitation was trivial or mild in $93 \%$ of patients examined (a mean of 59 months after repair) in most recent evaluation using angiography or echocardiography. More importantly, none of these patients had moderate or severe left $\mathrm{AV}$ valve stenosis and only two patients had mild left $\mathrm{AV}$ valve stenosis. Subsequently the 10-year actuarial survival is $91.3 \% \pm 0.04 \%$ and all of the longterm survivors are in New York Heart Association class I or II.

Our unique experience with consistent cleft closure over the past 20 years also gives us an opportunity to assess the effect of repair by means of cleft closure on patients with substantial preoperative AV valve regurgitation. The majority of patients with moderate or severe regurgitation before the operation had improved left $\mathrm{AV}$ valve function in the immediate postoperative period. Further improvement was observed at the time of discharge (see Fig. 2). Five percent to $10 \%$ of patients had no improvement in severity of left AV valve regurgitation after the operation, but none had progression (Appendix III).

Technical failure of the repair, including separation of previously sutured clefts or incomplete apposition of the valve leaflets, was detected in all of the patients requiring reoperation for left $\mathrm{AV}$ valve regurgitation. Reoperation for left AV valve regurgitation consisted of a second closure of the cleft or annuloplasty (or both), usually resulting in an excellent outcome. Only two patients eventually required valve replacement in our series and both died.

By multiple regression analysis, severe left AV valve regurgitation at immediate postoperative evaluation was recognized as a risk factor for early death and need for reoperation. The effect of annuloplasty in this difficult group of patients would be interesting. Annuloplasty was usually reserved for reoperation and only four patients had De Vega type annuloplasty or an annuloplasty as described by Capuoya, Laks and associates ${ }^{6}$ at the initial operation. This technique by Laks includes annuloplasty at the lateral commissures with multiple pericardial pledgets. The group from the University of Califor- 
Table VIII. Trends in patient distribution and surgical techniques between 1974 and 1995

\begin{tabular}{|c|c|c|c|c|c|c|c|c|c|}
\hline & \multicolumn{2}{|c|}{$1974-1979$} & \multicolumn{2}{|c|}{$1980-1984$} & \multicolumn{2}{|c|}{$1985-1989$} & \multicolumn{2}{|c|}{$1990-1995$} & \multirow[b]{2}{*}{$p$ Value } \\
\hline & $\%$ & No. & $\%$ & No. & $\%$ & No. & $\%$ & No. & \\
\hline Infants ( $\leq 1$ yr) & 1.0 & 2 & 19.0 & 8 & 45.2 & 33 & 73.1 & 49 & $<0.001$ \\
\hline Postop. PH crisis & 19.0 & 4 & 7.1 & 3 & 9.6 & 7 & 7.5 & 5 & NS \\
\hline PA banding & 76.2 & 16 & 73.8 & 31 & 35.6 & 26 & 28.4 & 19 & $<0.001$ \\
\hline Two-patch technique & 19.0 & 4 & 35.7 & 15 & 42.5 & 31 & 97.0 & 65 & $<0.001$ \\
\hline
\end{tabular}

$P H$, Pulmonary hypertension; $P A$, pulmonary artery; $N S$, not significant.

nia at Los Angeles used this technique on 63 of 105 patients $(60 \%)$ at initial repair with good results. ${ }^{6}$ Although annuloplasty at at initial attempt of repair may further improve the postoperative left $\mathrm{AV}$ valve function, this might also produce early or late left $\mathrm{AV}$ valve stenosis. Because no moderate or severe left AV valve stenosis occurred with our approach, we continue to use annuloplasty in highly selected patients.

Double-orifice left AV valve remains a significant cause of early mortality and need for reoperation in our series as with the larger experience from Boston. ${ }^{3}$ This rare but difficult condition was encountered in six patients $(3.0 \%)$ in our series and two patients required reoperation and subsequently died. These two patients had no cleft closure and massive left AV valve regurgitation resulted. The other four patients had partial cleft closure in which a technique similar to that described by Lee and associates ${ }^{14}$ from the Mayo Clinic was used. One patient died of acute ventricular failure. The remaining three patients did not require reoperation although mild to moderate left $\mathrm{AV}$ valve regurgitation persisted.

Although risk factor analysis did not demonstrate a statistically significant advantage of cleft closure in reducing the need for reoperation, this was not surprising because the majority of patients (93\%) had cleft closure whenever feasible. Because the common cause of reoperation in a series of trileaflet repairs was related to the fact that the cleft was not closed during the initial operation, ${ }^{2,15}$ management of the valve as a bileaflet structure has resulted in a low likelihood of reoperation for failure of left $\mathrm{AV}$ valve repair.

Pulmonary hypertensive crisis is the most frequent cause of early death (see Table II) and a highly significant risk factor for early deaths (see Table III), as well as need for major reoperation, according to multiple regression analysis (see Table VI). With improved postoperative management including prophylactic administration of nitroglycerin, nitroprusside, chlorpromazine, or prazosin hydrochloride, or a combination of these drugs, the incidence of this potentially fatal complication has been decreased from 19\% (1975 to 1979) to $7.5 \%$ (1990 to 1995) (see Table VIII). Early definitive repair before significant pulmonary vascular disease develops has also contributed to this improvement. Nonetheless, risk factor analysis for pulmonary hypertensive crisis is warranted because the only two early deaths since 1990 were related to this complication. Inhalation of nitric oxide may be beneficial in treating such patients.

Pulmonary artery banding did not predict either mortality or need for reoperation, probably because patients who died after pulmonary artery banding or who had definitive repair in another institution were not included in this study (Appendix I). Currently we prefer to perform complete repair in infancy before significant pulmonary vascular disease or congestive heart failure develops (see Table VIII). ${ }^{16}$ Pulmonary artery banding is considered for patients with multiple VSDs, severely imbalanced ventricles, prematurity, or other associated anomalies.

In summary, complete AV septal defects can be repaired in infancy with low mortality and good midterm to long-term outcome. Routine approximation of the cleft is safe and the likelihood of reoperation for left AV valve regurgitation is low. Most long-term survivors have mild or trivial left $A V$ valve regurgitation at most recent follow-up and all are in New York Heart Association class I or II. No deterioration in left $\mathrm{AV}$ valve function has been observed in any long-term survivors during a mean follow-up of 94 months.

\section{REFERENCES}

1. Studer M, Blackstone EH, Kirklin JW, et al. Determinants of early and late results of repair of atrioventricular repair of atrioventricular septal (canal) defects. J Thorac Cardiovasc Surg 1982;84:523-42.

2. Weintraub RG, Brawn WJ, Venables AW, Mee RBB. Two-patch repair of complete atrioventricular septal defect in the first year of life. J THORAC CARDIOVASC SURG 1990;99:320-6. 
3. Hanley FL, Fenton KN, Jonas RA, et al. Surgical repair of complete atrioventricular canal defects in infancy: twenty-year trends. J THORAC CARDIOvASC SURG 1993;106:387-97.

4. McGrath LB, Gonzalez-Lavin L. Actuarial survival, freedom from reoperation, and other events after repair of atrioventricular septal defects. J THORAC Cardiovasc Surg 1987;94:582-90.

5. Pozzi M, Remig J, Fimmers R, Urban AE. Atrioventricular septal defects: analysis of short- and medium-term results. J Thorac CaRdiovasc Surg 1991;101:138-42.

6. Capouya ER, Laks H, Drinkwater DC, Pearl JM, Milgalter E. Management of the left atrioventricular valve in the repair of complete atrioventricular septal defects. J Thorac CARDIOvaSC SURG 1992;104:196-203.

7. Rastelli GC, Kirklin JW, Titus JL. Anatomic observations on complete form of persistent common atrioventricular canal with special reference to atrioventricular valves. Mayo Clin Proc 1966;41:296-308.

8. Statistica for Windows, Statsoft, Inc. Tulsa: 1994.

9. Danielson GK. Atrioventricular septal defect with the "classic" (one-patch) operative approach. In: Moulton AL, ed. Congenital heart surgery: current techniques and controversies, Pasadina, California: Appleton Davies, 1984:136-50.

10. Lillehei CW, Anderson RC, Ferlic RM, Bonnabeau RC. Persistent common atrioventricular canal. J THORAC CARdiovasc SuRG 1969;57:83-94.

11. Kirklin JW. Atrioventricular canal defect. In Kirklin JW, Barratt-Boyes BG, eds. Cardiac surgery. 2nd ed. New York: Churchill Livingstone, 1993.

12. Bailey SC, Watson DC. Atrioventricular septal defect repair in infants. Ann Thorac Surg 1991;52:33-7.

13. Bove EL, Sondheimer HM, Kavey REW, Byrum CJ, Blackman MS. Results with the two-patch technique for repair of complete atrioventricular septal defect. Ann Thorac Surg 1984;38:157-61.

14. Lee CN, Danielson GK, Schaff HV, Puga FJ, Mair DD. Surgical treatment of double-orifice mitral valve in atrioventricular canal defects: experience in 25 patients. J Thorac Cardiovasc Surg 1985;90:700-5.

15. Cobanoglu A. Discussion of Capouya et al. ${ }^{6}$

16. Kirklin JW, Blackstone EH. Management of the infant with complete atrioventricular canal. J THORAC Cardiovasc Surg 1979;78:32-4.

\section{Discussion}

Dr. Gordon K. Danielson (Rochester, Minn.). The authors are to be congratulated on their excellent early and late results of repair of complete AV septal defect, or complete AV canal, as I was trained to call it. We agree with their assessment that creation of a competent left AV valve, alias mitral valve, it the cornerstone of surgical repair. The authors have discussed the relative merits of the two highly effective basic types of repair, the so-called classic one-patch repair, introduced by Drs. Kirklin and
Rastelli, and the two-patch repair, which was actually performed earlier by Dr. Lillehei in Minneapolis.

We also agree with the authors that the closure line or cleft of the anterior and posterior portions of the new anterior (septal) leaflet of the mitral valve is a weak point in the repair. Because we have also seen persistent or recurrent valve insufficiency in our patients and those of others when cleft closure was not done, we also favor at least a partial closure of the cleft.

[Slide] This slide shows freedom from reoperation for mitral insufficiency in our series stratified according to degree of residual postrepair mitral insufficiency as assessed by intraoperative double-sampling dye curves. Reoperation was much more likely in patients with moderate or severe insufficiency than in those with mild or no insufficiency. These data emphasize the importance of assessing the mitral valve intraoperatively with echocardiography and, if available, dye curves. We have found that dye curves better quantify the valve insufficiency and echocardiography provides better localization and characterization of the insufficiency.

The authors report no late progression of mitral insufficiency in their patients. This is at variance with our experience, in which a slow but progressive decline in freedom from reoperation for mitral insufficiency occurred over time. However, this averaged less than $1 \%$ per year over a 20 -year interval.

I was impressed that valve repair could be performed instead of valve replacement in six of the eight patients who required reoperation for severe valve insufficiency. This would imply that the repair had broken down or that it had not been adequate in the first place, rather than that there had been inadequate tissue for repair or the valve had a nonreconstructible lesion, such as double-orifice mitral valve. Put another way, I would like to ask the question: "Do only $1 \%$ of patients with complete AV canal have nonrepairable valves?"

Dr. Bando. Thank you for your kind comments, Dr. Danielson. Regarding the question as to why only two patients $(1 \%)$ required mitral valve replacement, our patient population was somewhat skewed because patients who had pulmonary artery banding and died before definitive repair were not included in this analysis. Thus patients who might otherwise have required mitral valve replacement may not have come to definitive repair.

Regarding the eight patients who required reoperation, three patients had dehiscence of the cleft closure and these patients had reapproximation of the cleft. Among two patients with double-orifice left $A V$ valve, one had a De Vega annuloplasty and one had mitral valve replacement. Two other patients had annuloplasty for inadequate valve tissue and one patient eventually had mitral valve replacement after failure of annuloplasty. It is our policy to use annuloplasty in highly selected patients at the initial attempt because this might produce early and late left $\mathrm{AV}$ valve stenosis. Because no moderate or severe left AV valve stenosis has been observed during the past 20 years, we continue to use this approach.

Dr. Frank L. Hanley (San Francisco, Calif.). It is generally agreed that the management of the left AV valve is the most critical part of the repair of this lesion; however, exactly how 
to manage the left $\mathrm{AV}$ valve remains a subject of controversy. Attention has centered around the trileaflet versus the bileaflet reconstruction. Clearly, competent valves can be achieved with the use of either technique, and, similarly, each technique can result in failure. It seems that the controversy distills down to the following issue.

The trileaflet valve is attractive because it preserves the leaflet tissue of the AV valve in this lesion in a natural configuration. The concern is that many who have used this technique, at least in young infants, have found that the results can be unpredictable, even in valves that were completely competent before the operation. The bileaflet repair, on the other hand, seems to provide more predictable early results; however, the nagging concern is that with leaflet scarring at the cleft closure site, long-term difficulties with either stenosis or distortion and late insufficiency potentially could be a problem.

The most important contribution of this study is that it provides long-term follow-up exclusively with the cleft closure technique. The results show that this type of repair holds up over time without stenosis and without degeneration of the valve. There are 63 patients with more than 10 years of follow-up with no trend toward valve degeneration. This information eliminates one of the major concerns with using the bileaflet approach.

I have three questions for the authors. In your series, three valves that failed showed evidence of dehiscence. Do you consider dehiscence to be a primary problem or a secondary problem resulting from poor alignment of leaflet tissue and subsequent tension?

The second question relates to pulmonary hypertension. You indicate that pulmonary hypertension seemed to decrease over time in your series. You also have shown that age at repair has decreased over time. Have you analyzed these two variables to determine if the decrease in pulmonary hypertension is linked to earlier age at repair?

Finally, you mentioned that since 1990 you have used primary repair rather than banding. During this time, $28 \%$ of patients had pulmonary artery banding. Can you identify the criteria you use presently to decide when you band and when you do not band?

Dr. Bando. I appreciate your comments, Dr. Hanley. Let me answer your last question first. The indications for the pulmonary artery band in the current era at our institution is multiple VSDs, significant imbalance that excludes a two-ventricle repair, or concomitant noncardiac disease such as sepsis or prematurity.

Your second question is related to the incidence of postoperative pulmonary hypertensive crisis. Early definitive complete repair and improvements in postoperative management have a major impact on the incidence of pulmonary hypertension crisis. We routinely use prophylactic chlorpromazine or prazosin hydrochloride, or both.

Your first question is related to the incidence of dehiscence and the repair technique of the left $A V$ valve. All the dehiscences in our experience occurred within the first 80 days after the operation. Repair of the left $A V$ valve with minimal valve tissue remains a challenge. Our current policy is to close the "cleft" if there is enough tissue and add a De Vega annuloplasty if necessary. However, we accept moderate regurgitation rather than creating significant left AV valve stenosis.
Dr. Hanley. I would like to make a final comment regarding pulmonary hypertension. Your specific pharmacologic management plan may be affecting the incidence of pulmonary hypertension; however, early repair itself prevents disease in the pulmonary vasculature. This factor may be responsible for the reduction in pulmonary hypertension.

Dr. Bando. We did not specifically evaluate the impact of the timing of repair on the incidence of postoperative pulmonary hypertensive crisis. However, we currently operate on younger patients, even before 3 months old, and this has had some impact inasmuch as significant pulmonary vascular disease may be uncommon in this group of patients.

Dr. Giovanni Stellin (Padova, Italy). Similar data from our institution, the University of Padova, have been presented at the meeting of the Castaneda Society. Over a period of 10 years, we have operated on 200 patients for AV septal defect. According to our statistical analysis, residual left $A V$ valve regurgitation is correlated with the presence of preoperative AV valve incompetence. Furthermore, the presence of left AV valve regurgitation is much lower in patients operated on before the age of 4 months. For this reason we now electively repair AV septal defect soon after the neonatal period at about the age of 1 or 2 months, just to avoid the onset of preoperative AV valve regurgitation. What is your experience in this matter and what is your ideal age at which to correct a complete form of AV septal defect?

Dr. Bando. According to our data, if preoperative AV valve regurgitation is divided into four different categories (none or trivial, mild, moderate, and severe), there was no significant correlation between severity of preoperative and postoperative regurgitation. However, if we categorize severe versus less than moderate, there is a significant correlation, as you mentioned. Recently we have preferred to perform definitive repair at 3 to 6 months of age, before severe AV valve regurgitation or irreversible pulmonary vascular disease develops.

Dr. Joseph J. Amato (New Hyde Park, N.Y.). I would like you to correlate two facts that you brought up. You stated that you closed $93 \%$ of the clefts, and you stated that three patients had single papillary muscles. We do not close the cleft on valves with single papillary muscles. I was wondering what the rate of incompetence was in those patients. Did you close the cleft, did you leave it open, and if you left it open, what was the percent of incompetence?

Dr. Bando. Among the three patients with single papillary muscle, one patient died of severe left $\mathrm{AV}$ valve regurgitation despite annuloplasty. Two patients are still surviving with mild to moderate left $\mathrm{AV}$ valve regurgitation. We also do not close the cleft among these patients.

Dr. Edward L. Bove (Ann Arbor, Mich.). May I ask one other point of clarification, specifically regarding the patients in the pulmonary artery banding group? Did any patients undergo banding and not come to repair because they died before repair or because they had inoperable defects, particularly some of the patients who might have had significant AV valve regurgitation?

Dr. Bando. Patients who had pulmonary artery banding and died before definitive repair or patients who had pulmonary artery banding and had definitive repair elsewhere were not included in this study. 
Appendix I. Patients with pulmonary artery banding without definitive repair

\begin{tabular}{lcccc}
\hline \multicolumn{1}{c}{ Patients } & $1974-1979$ & $1980-1984$ & $1985-1989$ & $1990-1995$ \\
\hline Died before definitive repair & 3 & 2 & 8 & 1 \\
Definitive repair elsewhere & 2 & 4 & 4 & 4 \\
Waiting for definitive repair & 0 & 0 & 0 & 4 \\
Total & 5 & 6 & 12 & 9 \\
\hline
\end{tabular}

Appendix II. Potential risk factors for mortality and need for reoperation

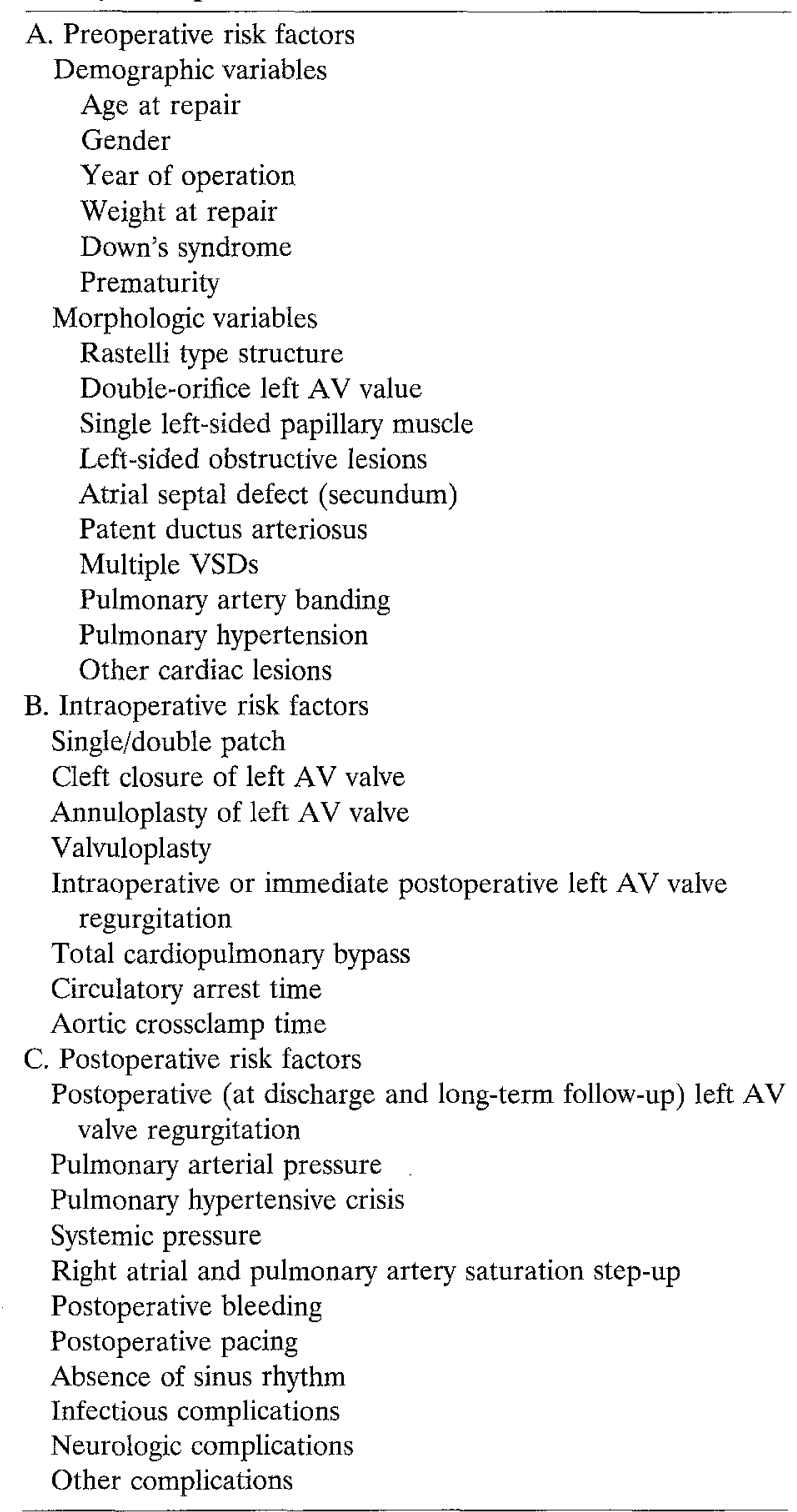

Appendix III. Change of left $A V$ valve function before and after repair of complete $A V$ septal defects

\begin{tabular}{clccc}
\hline $\begin{array}{c}\text { Preop. } A V \\
\text { valve regurgitation }\end{array}$ & Change & $\begin{array}{c}\text { Immediate } \\
\text { postop. }\end{array}$ & $\begin{array}{c}\text { Before } \\
\text { discharge }\end{array}$ & $\begin{array}{c}\text { Late } \\
\text { follow-up }\end{array}$ \\
\hline Severe & Severe & 1 & 0 & 0 \\
$(n=18)$ & Moderate & 11 & 4 & 1 \\
& Mild & 6 & 8 & 6 \\
& Tivial & 0 & 3 & 4 \\
& Death & - & 3 & 4 \\
& NA & - & - & 3 \\
Moderate & Severe & 0 & 0 & 0 \\
$(n=82)$ & Moderate & 8 & 2 & 4 \\
& Mild & 65 & 36 & 11 \\
& Trivial & 8 & 34 & 42 \\
& Death & 1 & 10 & 11 \\
& NA & - & - & 14 \\
Mild & Severe & 0 & 0 & 0 \\
$(n=76)$ & Moderate & 0 & 0 & 0 \\
& Mild & 24 & 15 & 12 \\
& Trivial & 52 & 58 & 48 \\
& Death & - & 3 & 3 \\
& NA & - & - & 13 \\
None & Severe & 0 & 0 & 0 \\
$(n=27)$ & Moderate & 0 & 0 & 0 \\
& Mild & 0 & 0 & 0 \\
& Trivial & 27 & 27 & 18 \\
& Death & - & - & - \\
& NA & - & - & 9 \\
\hline
\end{tabular}

